\title{
Brincando para Lembrar, Memória e Patrimônio na Contemporaneidade
}

\author{
Jugar a recordar, Memoria y Patrimonio en Contemporáneo \\ ${ }^{1}$ Ildaiane Pintanela Vergara; ${ }^{2}$ Rafael Teixeira Chaves; ${ }^{3}$ Yanne Alves Roberto; ${ }^{4}$ Carla \\ Rodrigues Gastaud \\ 1 ildaianevergara2010@ hotmail.com, Universidade Federal de Pelotas;
}

\begin{abstract}
Resumo
Este resumo pretende relatar algumas ações organizadas pelo Laboratório de Educação para o Patrimônio - LEP que envolvem a produção de material educativo e o desenvolvimento de ações educativas no âmbito do patrimônio cultural material e imaterial realizadas em museus da cidade de Pelotas, no Rio Grande do Sul. O LEP está vinculado ao curso de Museologia da Universidade Federal de Pelotas - UFPel entre seus objetivos refletir sobre os museus como agentes educativos e colaborar para a qualificação das ações educativas para o patrimônio desenvolvidas por estas instituições. Para isso, foi desenvolvida uma série de jogos para crianças e adultos, a fim de propiciar uma aproximação agradável, lúdica e pedagógica com alguns bens culturais da cidade de Pelotas que busca a transformação do ato de olhar a partir das ações educativas, resultando na construção de identidade através do referencial do patrimônio.
\end{abstract}

Palavras-Chave: Patrimônio, Educação, Museu, Ação Educativa, Instituição.

\section{Introdução}

As atividades realizadas pelo LEP - Laboratório de Educação para o Patrimônio é uma forma de aproximar os visitantes do patrimônio da cidade através de jogos. As ações educativas afinam a comunicação do museu com o público valorizando o patrimônio cultural e a memória social. Estes procedimentos promovem a educação que tem o acervo como centro de suas atividades.

O fundamento da ação educativa é a relação entre o acervo e o público que o visita, atuando por meio de estímulos capazes de estabelecer diálogos com os visitantes e facilitando a apreensão pelo público, isto é, gerando respeito e valorização pelo patrimônio cultural, ou como define a publicação "Educação Patrimonial: Histórico, Conceitos e Processos", do IPHAN:

\footnotetext{
(...) a Educação Patrimonial constitui-se de todos os processos educativos formais e não formais que têm como foco o Patrimônio Cultural, apropriado socialmente como recurso para a compreensão sócio-histórica das referências culturais em todas as suas manifestações, a fim de colaborar para seu reconhecimento, sua valorização e preservação. Considera ainda que os processos educativos devem primar pela construção coletiva e democrática do conhecimento, por meio do diálogo permanente entre os agentes culturais e sociais e pela participação efetiva das comunidades detentoras e produtoras das referências culturais, onde convivem diversas noções de Patrimônio Cultural.
}

É importante salientar que este ato de educar não dever ter papel meramente acumulativo de saberes, mas de valorização da própria história cultural e de afirmação de 
identidade, estimulando o compromisso com a preservação e com a produção de novos conhecimentos.

\section{Objetivos}

E por que fazer ações educativas? Segundo Denise Grinspum desde que o museu se tornou público no século XVIII é a sua função social que justifica a sua existência. Atualmente o compromisso sócio-político dos museus é, antes de tudo, educacional e sua nova definição aponta para 'instituições de serviço público e educação, um termo que inclui exploração, estudo, observação, pensamento crítico, contemporâneo e diálogo" (2000, p.02).

Neste sentido, o Laboratório de Educação para o Patrimônio, LEP, laboratório de ensino do Curso de Museologia, propõe aos alunos do curso o desafio de desenvolver ações educativas para o patrimônio mais especificamente neste ano de 2015 , o desafio de construir jogos para museus - a partir da reflexão necessária sobre como as comunidades se identificam com os bens patrimoniais, na busca de que as ações educativas sejam um modo de ampliar o olhar que se dirige ao patrimônio, fortalecendo identidades culturais.

\section{Metodologia}

A inspiração para o desenvolvimento dessas ações educativas vem da coleção de materiais educativos que o LEP recebe de instituições de todo o país e que compõem a sua Mediateca. A Mediateca iniciou em 2012 e tem como propósito reunir e disponibilizar para consultas todo o tipo de material educativo e de divulgação produzido por museus e por instituições voltadas para o patrimônio.

A partir destes materiais, e das condições e interesses locais, são criados os jogos e atividades que o Laboratório oferece às instituições locais, através dos quais os alunos do Bacharelado em Museologia têm a oportunidade de experimentar e realizar diferentes tipos de ação educativa. São atividades duplamente compensadoras: ganham os visitantes dos museus e ganham, também, os futuros museólogos que ampliam seu referencial e praticam o que aprendem no Curso.

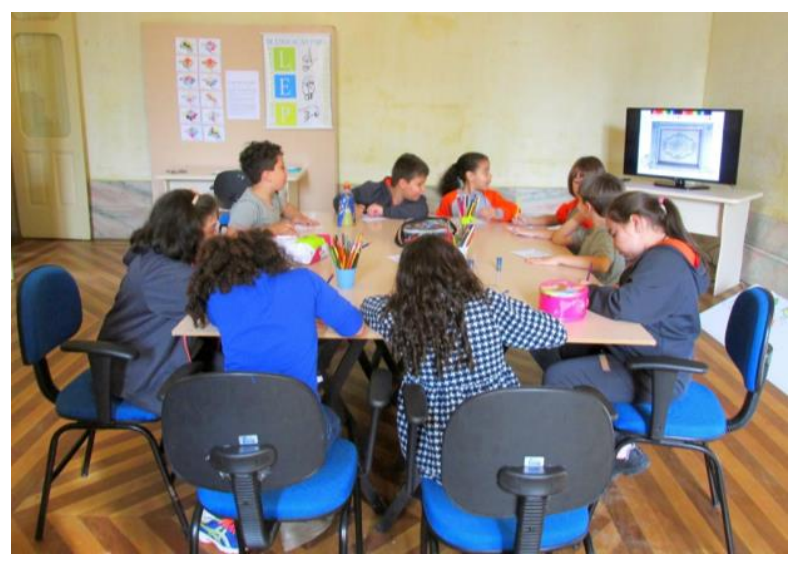

Fotografia 1 - Atividades aplicadas no dia do Patrimônio 2015 no Museu do Doce da UFPel. Fonte: LEP - Laboratório de Educação para o Patrimônio, 2015.

Embasados na fundamentação teórica obtida a partir de leitura e discussão de autores como Denise Grinspum, Maria de Lourdes Horta, Cristina Bruno, Paulo Freire, Maria Célia Santos, entre outros, e aliando estes princípios a permanente experimentação, foi elaborado em 2014 um primeiro conjunto formado por três jogos com foco no patrimônio cultural de Pelotas: o primeiro, "Quebra-cabeça da Praça", é um quebra-cabeça, com imagens dos 
casarões do entorno da Praça Coronel Pedro Osório; o segundo nomeado pelos próprios participantes como "Pife Doce" é um jogo de cartas sobre os doces inventariados no INRC (Inventário Nacional de Referências Culturais); o terceiro, "Que casa é?", é um jogo de trilha no qual, sobre a planta baixa da Praça Coronel Pedro Osório, devem ser identificados e localizados casarões do centro histórico de Pelotas.

Em 2015, foram implementadas duas novas propostas: a primeira, relacionada ao universo histórico do Museu da Baronesa, é um jogo de percurso embasado nas cartas de viagem escritas por cinco personagens que viveram na casa, atualmente museu. O Museu da Baronesa é um dos importantes lugares de preservação da memória da cidade de Pelotas. Ele está contextualizado no final do século XIX e início do século XX, época marcante no passado da cidade de Pelotas/RS. A segunda, intitulada: Colorir para conhecer: detalhes do Museu do Doce da UFPel, foi inspirada no sucesso dos atuais livros de colorir, a ação proposta pretende que os participantes aprendam brincando e pintando ilustrações produzidas, num primeiro momento, a partir dos estuques decorados dos forros do Museu do Doce da UFPel, possibilitando uma observação atenta dos detalhes que embelezam a edificação. $\mathrm{O}$ ato de colorir pode provocar diversas sensações e ao mesmo tempo estimula a expressão e a curiosidade, dentro do próprio museu.

\section{Resultados}

A reflexão sobre materiais educativos de instituições, que se tornam fonte de referência, criando este banco de repertórios que são um recurso para que os profissionais e estudantes possam ter estímulos capazes de estabelecer diálogos e com isto adaptando para a nossa região e nossos patrimônios assim valorizando o patrimônio cultural, e evocando memórias através dos materiais educativos ampliando o olhar e percepção.

Estas ações educativas produzidas pelo LEP aproximam os públicos dos bens patrimoniais por meio do ato de brincar. Assim, podemos perceber que as ações educativas é uma forte integração de educação e patrimônio.

De acordo com Magali Cabral (2002), se o patrimônio é terreno em construção, fruto de eleição, campo de combate, espaço de relações humanas, é também "meio de comunicação e campo de educação", podendo e devendo ser objeto de ações educativas que contribuam para a mudança social por "ensinar a pensar criticamente, fornecendo os instrumentos básicos para o exercício da cidadania".

\section{Referências}

CABRAL, Magali. Comunicação, educação e patrimônio cultural. Texto apresentado no Fórum Estadual de Museus do Rio Grande do Sul. Inédito. Rio Grande, Rio Grande do Sul, 2002.

GASTAUD, Carla, CRUZ, Patrícia, LIMA, Marcelo; Implantação da Mediateca do LEP Laboratório de Educação para o Patrimônio ago de 2013.

GASTAUD, Carla Rodrigues; CRUZ, Matheus; LEAL, Noris Mara Pacheco Martins; SÁ, Patrícia Cristina da Cruz; CASTRO, Renata Brião de. Do sal ao açúcar: as ações educativas do Museu do Doce da UFPel (Universidade Federal de Pelotas). Expressa Extensão. Pelotas, v.19, n.2, p. 91-105, 2014.

MAGALHÃES, Leandro Henrique; BRANCO, Patrícia Martins Castelo; ZANON, Elisa Roberta. Educação Patrimonial: Da Teoria à Prática. Londrina-PR: UniFil, 2009. 
GRINSPUM, Denise. Educação para o patrimônio: Museu de Arte e Escola-Responsabilidade compartilhada na formação de públicos. 2000. Tese de Doutorado. Faculdade de Educação, USP, São Paulo.

Portal Aprendiz. <http:portal.aprendiz.uol.com.br/2015/07/07/educacao-patrimonial-eaprender-com-o-mundo-e-a-cultura-que-construimos>. Acesso em: 25/10/2015.

Museu da Baronesa, Pelotas - RS. Disponível em: 〈http://www.museudabaronesa.com.br>. Acesso: 26/10/2015. 